\title{
Demographic Prevalence of Drug Abuse in youth: Cases from the Surkhet District of Nepal
}

\author{
Dhanush Chandra Pathak \\ PhD Scholar, Mewar University, Rajasthan, India \\ Email: pdhanushchandra@gmail.com
}

\begin{abstract}
Any substance used in chemistry, dyeing, or any technical process or mix or adulterate with a drug, esp. a narcotic or prison. Drug abuse as a term used to indicate the excessive use of a drug, regardless of whether an individual has reached the point of true dependence on it, or not. The main objective of this study is to identify the demographic prevalence of drug abuse among youth in Surkhet district. Quantitative research method was used to draw the data from 29 respondents of Birendranagar valley of Nepal. Simple Random sampling technique was used to select the respondents. Frequency table was generated for quantitative data. Demographic factors and pattern were taken to identify the demographic prevalence of drug abuse. Demographic factors had covered age, family, castelethnicity, education, occupation and marital status. Likely pattern factors had covered place where they use drug, what types of drug they use and with whom they use drug. Among them, majority respondents reported they use mostly drug use age is between 21 - 25. Likewise Brahmin/Chhetri Caste and ethnicity used more drug to compare others caste. Equally more prevalence of drug use can see in Nuclear Family.
\end{abstract}

\section{KEYWORDS}

Demographic, Drug, Nepal, Prevalence, Youth

\section{INTRODUCTIONS}

The situation of drug abuse among Nepalese youth now appears to be such that it has no place for ignorance what is happening. It has caused moral and cultural deterioration. Drug abuse means the use of illegal drugs or misuse of legal drugs on pressure and continuing to involve in such activities even after knowing the negative consequences. Furthermore, University of Maryland Medical Center defines drug abuse is the repeated use of illegal drugs or misuse of prescription of legal drugs with negative consequences. Consequences may be problems at work, school, home or relationships (University of Maryland Medical Center, 2015). There are so many causes which push youth in drug dependence In the context of Nepal these push factors include peer pressure, curiosity and the lack of awareness (UNODC, 2013). There are many causes of drug abuse claimed by Dr Neil L Bernstein are imitating other people( because other people are doing it), media, boredom, rebellion, instant gratification, lack of confidence, misinformation (Bernstein). National institute on drug abuse (Bernstein, 2015). Unlike National Institute on Drug Abuse claims the causes of drug abuse are to feel better, curiosity, peer pressure, home family and school. (National Institute on Drug Abuse, 2014, pp. 9-10). 
So regarding the drug abuse this study is going to explore the demographic prevalence of drug abuse among youth in Surkhet district.

\section{METHOD}

This study was conducted in the Birendnagar valley in 2014. Research was based on the descriptive research design. The simple random sampling technique was used to select the respondents. Total 29 male respondents were selected from the Benevolence Rehabilitation Center, Birendranagr, Surkhet) for the questionnaire survey. The questionnaire method was used to collect the data. The result was drawn from the primary data and critically discussed with the secondary data. Frequency table was drawn from quantitative data by using the SPSS.

\section{RESULT}

The study has presented the data in tabular form. The presented data covers the analysis of distribution of demographic characteristics of respondents as well as it has also analyzed the pattern of drug use.

\section{Demographic Prevalence of Drug Abuse}

The aim of generating these tables is to show the demographic prevalence and patterns of drug abuse in Surkhet district of Nepal.

Table 1: Age distribution of drug abuser in Surkhet district

\begin{tabular}{|c|c|c|}
\hline \multicolumn{3}{|c|}{ Age } \\
\hline Years & Frequency & Percent \\
\hline Below 15 & 1 & 3.4 \\
\hline $16-20$ & 5 & 17.2 \\
\hline $21-25$ & 7 & 24.1 \\
\hline $26-30$ & 6 & 20.7 \\
\hline $31-35$ & 1 & 3.4 \\
\hline $36-40$ & 6 & 20.7 \\
\hline 41 and above & 3 & 10.3 \\
\hline Total & 29 & 100.0 \\
\hline
\end{tabular}

Source: field survey 2014

Table 1 presents the age of respondent. The result shows that the maximum number of drug abuser found the age between 21 to 25 years. Similarly, the result of percentage shows that on the same age group 24.1 is the highest percentage of drug abuser in Surkhet district. 
ISSN: 2362-1303 (Paper) | elSSN: 2362-1311(Online)

JOURNAL OF ADVANCED ACADEMIC RESEARCH (JAAR)

Table 2 Caste and Ethnicity distribution of drug abuser in Surkhet valley

\begin{tabular}{|c|c|c|}
\hline \multicolumn{3}{|c|}{ Caste / Ethnicity } \\
\hline Caste / Ethnicity & Frequency & Percent \\
\hline Brahmin/Chhetri & 16 & 55.2 \\
\hline Janajati & 6 & 20.7 \\
\hline Dalit & 3 & 10.3 \\
\hline Thakuri & 4 & 13.8 \\
\hline Total & 29 & 100.0 \\
\hline
\end{tabular}

Source: field survey 2014

Table 2 shows the caste / ethnicity of respondent. The result shows the maximum and minimum number of drug abusers found the caste / ethnicity from Brahmin/Chhetri to Dalit. Similarly the result shows that the maximum drug abusers fall under the Brahmin/Chhetri caste having 55.2 percentage and minimum drug abusers are fall under the Dalit Caste / Ethnicity having 10.3 percentages.

Table 3 Types of family distribution of drug abuser in surkhet valley

\begin{tabular}{|c|c|c|}
\hline \multicolumn{3}{|c|}{ Family } \\
\hline Types of family & Frequency & Percent \\
\hline Nuclear & 20 & 69.0 \\
\hline Joint & 9 & 31.0 \\
\hline Total & 29 & 100.0 \\
\hline
\end{tabular}

Source: field survey 2014

Table 3 shows the types of family of respondent. The result shows that highest number of drug abusers in surkhet valley. Among them youth who belongs to nuclear types of family is highest drug abusers carrying 69.0 Percent and youth who belongs to joint family is lowest drug abuser with 31.0 Percent.

Table 4 Education Qualification distribution of drug abuser in surkhet valley

\begin{tabular}{|c|c|c|}
\hline \multicolumn{3}{|c|}{ Education } \\
\hline Education Qualification. & Frequency & Percent \\
\hline literate & 2 & 6.9 \\
\hline Literate & 5 & 17.2 \\
\hline Primary & 1 & 3.4 \\
\hline Secondary & 10 & 34.5 \\
\hline Higher secondary & 7 & 24.1 \\
\hline Bachelor & 3 & 10.3 \\
\hline Master \& above & 1 & 3.4 \\
\hline Total & 29 & 100.0 \\
\hline
\end{tabular}

Source: field survey 2014

Table no 4 shows the education qualification of o respondent. The highest drug abusers have secondary education qualification with the 34.5 Percent. Followed by higher secondary 
education qualification with 24.1 Percent. 17.2 percentages of drug abusers have Literate education qualification and the minimum drug abusers who have Master $\&$ above education qualification carries 3.4 percentages.

Table 5 occupations distribution of drug abuser in surkhet valley

\begin{tabular}{|c|c|c|}
\hline \multicolumn{3}{|c|}{ Occupation } \\
\hline Types of occupations & Frequency & Percent \\
\hline Job & 5 & 17.2 \\
\hline Business & 2 & 6.9 \\
\hline Agriculture & 3 & 10.3 \\
\hline Unemployed & 19 & 65.5 \\
\hline Total & 29 & 100.00 \\
\hline
\end{tabular}

Source: field survey 2014

Table no 5 shows that types of occupation of drug abuser. The highest number of drug abusers is unemployed with 65.5 percentages which is followed by job with 17.2 percent. Only 10.3 percent abusers occupation is agriculture and 6.9 percent of drug abusers are involved in business.

Table 6 Marital status distribution of drug abuser in Surkhet valley

\begin{tabular}{|c|c|c|}
\hline \multicolumn{3}{|c|}{ Marital Status } \\
\hline Marital status & Frequency & Percent \\
\hline Unmarred & 15 & 51.7 \\
\hline Married & 10 & 34.5 \\
\hline Separated & 3 & 10.3 \\
\hline Widow/Widower & 1 & 3.4 \\
\hline Total & 29 & 100.0 \\
\hline
\end{tabular}

Source: field survey 2014

Table no 6 shows that marital status of drug abusers. The highest 51.7 percentage of drug abusers are unmarried and minimum 3.4 percentage of drug abusers are Widow/Widower.

\section{Pattern of Drug Abuse}

The aim of generating these tables is to show the patterns of drug abuse in Surkhet district of Nepal. 
ISSN: 2362-1303 (Paper) | elSSN: 2362-1311(Online)

JOURNAL OF ADVANCED ACADEMIC RESEARCH (JAAR)

Table 7 distribution of Drug Starting Age of respondents as a drug abuse in Surkhet valley

\begin{tabular}{|c|c|c|}
\hline Starting Age of respondents as a drug abuse & \multirow{2}{*}{ Frequency } & Percent \\
\hline Years & 13 & 44.8 \\
\hline Below 15 & 12 & 41.4 \\
\hline $16-20$ & 3 & 10.3 \\
\hline $21-25$ & 1 & 3.4 \\
\hline $26-30$ & 29 & 100.0 \\
\hline Total & &
\end{tabular}

Source: field survey 2014

Table no 7 shows that pattern of drug abuse. This table describes the percentage of drug abusers in different age group. The most youth who are drug abusers are fall under the age group of below 15 having 44.8 Percent. This number is carried out by age group of 16-20 which have 41.4 percentage and the minimum drug abusers are fall under the age group of 26-30 having 3.4 percentage.

Table 8 place of drug use first time distribution of drug abusers in surkhet valley

\begin{tabular}{|c|c|c|}
\hline \multicolumn{3}{|c|}{ Where did you use drug first time? } \\
\hline Place of drug use & Frequency & Percent \\
\hline Own Home & 4 & 13.8 \\
\hline Friend's Home & 10 & 34.5 \\
\hline Under the Bridge & 1 & 3.4 \\
\hline In the Jungle & 6 & 20.7 \\
\hline Total & 21 & 72.4 \\
\hline Missing System & 8 & 27.6 \\
\hline Total & 29 & 100.0 \\
\hline
\end{tabular}

Source: field survey 2014

Table no 8 shows the place where drug abuser use drug first time. Maximum abuser 34.5 percentages is use drug first time to their friend's home. And 20.7 percent of drug abuser first time use drug in the jungle and lowest percent 3.4 percent of abuser use under the bridge.

Table 9 cigarette smoking distribution of drug abuser in Surkhet valley

\begin{tabular}{|c|c|c|}
\hline \multicolumn{3}{|c|}{ Do you smoke cigarette? } \\
\hline & Frequency & Percent \\
\hline Yes & 28 & 96.6 \\
\hline No & 1 & 3.4 \\
\hline Total & 29 & 100.0 \\
\hline
\end{tabular}

Source: field survey 2014 
Table no 9 shows that almost all 96.6 percent respondent use cigarettes and only 3.4 percent respondent don't use cigarette.

Table 10 Distribution of category of drug use first time of drug abuser in Surkhet valley

\begin{tabular}{|c|c|c|}
\hline \multicolumn{3}{|c|}{ Which drug did you use first time? } \\
\hline & Frequency & Percent \\
\hline Alcohol only & 19 & 65.5 \\
\hline Ganja only & 9 & 31.0 \\
\hline Alcohol and ganja & 1 & 3.4 \\
\hline Total & 29 & 100.0 \\
\hline
\end{tabular}

Source: field survey 2014

Table no 10 shows that drug use first time by abuser is maximum alcohol which has 65.5 percent similarly followed by ganja only 31.0 percent and minimum drug used first time is Alcohol and ganja 3.4 percent.

Table 11: Place wise distribution of drug mostly use

\begin{tabular}{|c|c|c|}
\hline \multicolumn{3}{|c|}{ Where did you mostly use drug? } \\
\hline Place & Frequency & Percent \\
\hline At home & 4 & 13.8 \\
\hline At school or college & 2 & 6.9 \\
\hline At friend's home & 2 & 6.9 \\
\hline In the street or park & 6 & 20.7 \\
\hline In the restaurant & 15 & 51.7 \\
\hline Total & 29 & 100.0 \\
\hline
\end{tabular}

Source: field survey 2014

Table no 11 shows that Place wise distribution of drug mostly use. Maximum 51.7 percent of respondent mostly use drug in the restaurant, followed by in the park and street 20.7 percent and minimum respondent response they use drug at school or college and at friend's home 6.9 percent respectly.

Table 12 Distribution of drug partner of drug abuse in Surkhet valley

\begin{tabular}{|c|c|c|}
\hline \multicolumn{3}{|c|}{ With whom did you use drug? } \\
\hline Person & Frequency & Percent \\
\hline Alone & 12 & 41.4 \\
\hline With friend & 17 & 58.6 \\
\hline Total & 29 & 100.0 \\
\hline
\end{tabular}

Source: field survey 2014

Table no 12 shows that drug partner of drug abuser. Majority 58.6 percent respondent use drug with their friends and only 41.4 percent use drug alone. 


\section{DISCUSSIONS}

The above explained demographic prevalence of drug abuse in youth was discussed in previous literature on the basis of age, ethnicity, education, family background etc. A study conducted by Ramesh Raj Kunwor titled 'Nepalese Society: Liquor and culture', states there are some Kshatriyaa caste called Matawali Chhetris who lived in Karnali region are acceptable to take liquor by their culture and they are traditionally recognized as a habitual alcohol drinkers.

A report conducted by Center for Behavioral Health Statistics and Quality (CBHSQ), Substance Abuse and Mental Health Services Administration (SAMHSA), U.S. Department of Health and Human Services (HHS), and by RTI International (Research Triangle Institute), 2014 claims that in 2013, an estimated 24.6 million (9.4\%) Americans aged 12 or older were current (past month) illicit drug users except alcohol. In 2013, marijuana was the most commonly used illicit drug, with 19.8 million current (past month) users. It was used by 80.6 percent of current illicit drug users. Slightly 136.9 million current drinkers in 2013 more than half (52.2 percent) of Americans aged 12 or older (Substance Abuse and Mental Health Services Administration, 2014, p. 15 \& 35). Likewise, the highest rate of current illicit drug use was among 18 to 20 year olds (22.6 percent (Substance Abuse and Mental Health Services Administration, 2014, p. 19).

In 2013, among persons aged 12 or older, the rate of current illicit drug use was 3.1 percent among Asians, 8.8 percent among Hispanics, 9.5 percent among whites, 10.5 percent among blacks, 12.3 percent among American Indians or Alaska Natives, 14.0 percent among Native Hawaiians or Other Pacific Islanders, and 17.4 percent among persons reporting two or more races. Illicit drug use in 2013 varied by the educational status of adults aged 18 or older. The rate of current illicit drug use was lower among college graduates (6.7 percent) than those with some college education but no degree (10.8 percent), high school graduates with no further education ( 9.9 percent), and those who had not graduated from high school (11.8 percent) (Substance Abuse and Mental Health Services Administration, 2014, p. 26).

Current illicit drug use differed by employment status in 2013. Among adults aged 18 or older, the rate of current illicit drug use was higher for those who were unemployed (18.2 percent) than for those who were employed full time (9.1 percent), employed part time (13.7 percent), or "other" (6.6 percent) (which includes students, persons keeping house or caring for children full time, retired or disabled persons, or other persons not in the labor force). The percentage of adults employed full time who were current illicit drug users in 2013 was similar to that in 2012 (8.9 percent) (Substance Abuse and Mental Health Services Administration, 2014, p. 28).

Shannon Stagman and his friends 2009 stated that, 7.3\% marijuana use of youth between 1217 years. Similarly rates of current alcohol use were 3.5 percent among persons aged 12 or 13, 13 percent of persons aged 14 or 15, and 26 percent for 16 or 17 year olds Among youths ages 12 to 17 in 2009, Asians had the lowest rates of current alcohol use (6.5 percent), compared to 10.6 percent of African-Americans, 11.9 percent of American Indians or Alaska Natives, 15.2 percent of Hispanics/Latinos, 16.1 percent of whites, and 16.7 percent of multiracial youths(Stagman, Schwarz, \& Powers, 2011). 
Substance Abuse and Mental Health Services Administration, 2010 claims that in 2009, 10.9\% of adolescents reported at least one episode of hazardous drinking (binge drinking or heavy drinking) during the past month. This percentage is nearly identical to 2008 (10.8\%). Marijuana was the most frequently used illicit drug, with $7.3 \%$ of respondents reporting past month use in 2009. This percentage was significantly higher than the percentage for $2008(6.7 \%)$, suggesting that marijuana use among adolescents may be increasing (Butler Center for Research, 2010).Jing Wang and his friends 2009 find out that the percentages of adolescents who had experience with drinking alcohol, being drunk, smoking cigarettes, or using marijuana for at least once in the last 30 days. About $32 \%$ of adolescents had drunk alcohol and $18.1 \%$ had been drunk in the past 30 days, $13.6 \%$ had smoked cigarettes, and $8.9 \%$ had used marijuana. African-American adolescents reported less substance use and Hispanic adolescents reported more use. With adolescents from two-parent families as the referent, those from all five non-intact families reported more substance use. Family affluence had a positive relation with substance use, but the magnitude of the association was small. With two-parent family structure as the referent, the adolescent substance use difference between two-parent family structure and father-stepmother or other family structure was still significant, but there was no difference between adolescents from two-parent and those from mother-only, father-only, or mother-stepfather family structures (Wang, Simons-Morton, Farhart, \& Luk, 2009, pp. 5-7). Alcohol was more likely to have been consumed by older than younger youth and less likely by African American youth than youth of other racial groups. Alcohol was more likely to be consumed by older youth, Hispanics, and those who were not attending school at the time of entry. Youth living with both biological parents were also more likely to have used alcohol in the past year. African Americans and school attendees were less likely to be heavy drinkers, and youth who were living with their biological parents were more likely to drink alcohol heavily. Illicit drug use among incarcerated juveniles was more than twice that of 8th, 10th, and $12^{\text {th }}$ grade students in Illinois (Cho, Johnson, \& Graf, 2000, pp. 12-14 \& 26).

Annual prevalence of marijuana was up in 8th and 10th grades, albeit by non-significant amounts, increasing by 1.2 and 1.8 percentage points respectively. In 12th grade, annual use of marijuana remained unchanged (0.0). For the three grades combined, annual prevalence of marijuana was up by 1.1 percentage points (Johnston, O’Malley, Miech, Bachman, \& Schulenberg, 2014, p. 5).

\section{CONCLUSION}

The study explored that more prevalence of drug can see age group of $21-25$. Most of the abusers are belongs to Brahmin/Chhetri caste and ethnicity similarly respondent belongs to nuclear family are more involved in drug abuse. Most of the education qualification of respondent is secondary level likewise maximum respondent are unemployed. More prevalence of drug can see to unmarred. The study explored that majority of drug abuser use drug in their friend's home. Similarly almost all drug abusers use cigarette. Majority respondent use alcohol to compare janga and brown sugar. Most of the place where they use drug is in the restaurant. Most of the respondent use drug with friend. Further study can be conducted to 
explore the socio culture causes of drug abuse in the context of Sukhet district which can contribute to understand drug abuse and its preventive measures.

\section{ACKNOWLEDGEMENT}

I gratefully acknowledge to Dr. Tej Bahadur Karki Research Coordinator, Southwestern Centre for Research \& PhD Studies for his close supervision during my research and I am also thankful to Mewar University. My thanks are deserves Mr. Pawan Bhattrai managing director of Benevolence Rehabilitation Center, Surkhet.

\section{REFERENCES}

Bernstein, N. I. (2015). Top 8 Reasons why Teens Try Alcohol and Drugs. Retrieved August 15, 2015, from www.Partnership for Drug-Free Kids.com: http://www.drugfree.org/resources/top-8-reasons-why-teens-try-alcohol-and-drugs/

Butler Center for Research. (2010). Research Update. Center City ,Chisago: Butler Centerfor Research.

Cho, Y. I., Johnson, T., \& Graf, I. (2000). Alcohol, Tobacco, and Other Drug Use Among Youth Entering Juvenile Correctional Facilities in Illinois:Prevalence and Treatment Need, 2000. Illinois Department of Human Services. Chicago, Illinois: Survey Research Laboratory,College of Urban Planning and Public Affairs,University of Illinois at Chicago.

DUBE, D. J. (2007). SOCIAL FACTORS INFLUENCING ADOLESCENT DRUG ABUSE IN HIGH SCHOOLS IN ATTERIDGEVILLE. TSHWANE UNIVERSITY OF TECHNOLOGY.

Johnston, L. D., O’Malley, P. M., Miech, R. A., Bachman, J. G., \& Schulenberg, J. E. (2014). Monitoring the Future national results on drug use: 1975-2013:Overview, Key Findings on Adolescent Drug Use. Ann Arbor: Institute for Social Research,The University of Michigan.

National Institute on Drug Abuse. (2014). Drugs, Brains, and Behavior The Science of Addiction. Maryland: National Institute of Health.

Stagman, S., Schwarz, S. W., \& Powers, D. (2011). Adolescent Substance Use in the U.S.Facts for Policymakers. Mailman School of Public Health, Department of Health Policy and Management. New York: Columbia University.

Substance Abuse and Mental Health Services Administration. (2014). Results from the 2013 National Survey on Drug Use and Health:Summary of National Findings. Rockville, MD: Substance Abuse and Mental Health Services Administration Center for Behavioral Health Statistics and Quality.

University of Maryland Medical Center. (2015). Drug abuse. Retrieved August 15, 2015, from Maryland Medical Center: http://umm.edu/health/medical/ency/articles/drug-abuse 
UNODC. (2013, July 30). Nepal: Discussing drug abuse in schools - youth centric programmes help in creating awareness. Retrieved Auguste 15, 2015, from www.unodc.com: https://www.unodc.org/southasia//frontpage/2013/July/nepal-discussing-drug-abusein-schools.html

Wang, J., Simons-Morton, B. G., Farhart, T., \& Luk, J. W. (2009). Socio-Demographic Variability in Adolescent Substance Use:Mediation by Parents and Peers. National Institute of Health , 10 (4), 387-396. 